\title{
Achievement emotions mediate the link between goal failure and goal revision: evidence from digital learning environments
}

Article

Accepted Version

Creative Commons: Attribution-Noncommercial-No Derivative Works 4.0

Theobald, M., Breitweiser, J., Murayama, K. and Brod, G. (2021) Achievement emotions mediate the link between goal failure and goal revision: evidence from digital learning environments. Computers in Human Behavior, 119. 106726. ISSN 0747-5632 doi:

https://doi.org/10.1016/j.chb.2021.106726 Available at https://centaur.reading.ac.uk/96000/

It is advisable to refer to the publisher's version if you intend to cite from the work. See Guidance on citing.

To link to this article DOI: http://dx.doi.org/10.1016/j.chb.2021.106726

Publisher: Elsevier

All outputs in CentAUR are protected by Intellectual Property Rights law, including copyright law. Copyright and IPR is retained by the creators or other copyright holders. Terms and conditions for use of this material are defined in the End User Agreement. 


\section{www.reading.ac.uk/centaur}

\section{CentAUR}

Central Archive at the University of Reading

Reading's research outputs online 
Achievement Emotions Mediate the Link between Goal Failure and Goal Revision: Evidence from Digital Learning Environments Maria Theobald ${ }^{1,2}$, Jasmin Breitwieser ${ }^{1,2}$, Kou Murayama $^{3,4}, \&$ Garvin Brod ${ }^{1,2,5}$

${ }^{1}$ DIPF | Leibniz Institute for Research and Information in Education, Frankfurt, Germany ${ }^{2}$ Center for Individual Development and Adaptive Education of Children at Risk (IDeA), Frankfurt, Germany ${ }^{3}$ Department of Psychology, University of Reading, Reading, United Kingdom ${ }^{4}$ Research Institute, Kochi University of Technology, Japan ${ }^{5}$ Department of Psychology, Goethe University, Frankfurt, Germany

\section{Correspondence}

Maria Theobald, DIPF | Leibniz Institute for Research and Information in Education, Rostocker Str. 6, 60323 Frankfurt am Main, Germany. E-mail: theobald@dipf.de 


\begin{abstract}
The present study tested how students emotionally react to and deal with goal failure. We (1) examined students' achievement emotions after they failed to achieve their learning goal and (2) tested whether students' achievement emotions after goal failure predicted goal revision. We tested medical students $(N=344)$ who used a digital learning platform to prepare for a high-stakes exam. Students reported their learning goals (before studying) and their anger, tension, joy, and pride (after studying) each day over the course of 40 days. Daily goal achievement was assessed objectively via logfiles. Multilevel analyses revealed that goal failure on a particular day predicted higher anger and tension and lower joy and pride. After goal failure, students generally downregulated their goal the next day, and the more so the farther they had missed their goal. Achievement emotions mediated this link, however. Students who reported stronger negative emotions (i.e., more anger, less joy, and less pride) down-regulated their goals to a lesser extent. Together, results suggest that goal revision depends on previous goal achievement, but also on students' achievement emotions after goal failure.
\end{abstract}

Keywords: achievement emotions, goal failure, goal setting, goal revision, self-regulated learning, web-based learning 


\section{Highlights}

- Goal failure predicted more anger, more tension, less joy, and less pride.

- Students down-regulated their goals after goal failure - especially if they widely missed their goals.

- Achievement emotions mediated this link.

- Students down-regulated their goals to a lesser extent if they reported more anger, less joy, and less pride after failure.

- Goal revision likely depends on previous goal achievement but also on students' achievement emotions after goal failure. 


\section{EMOTIONS MEDIATE THE LINK BETWEEN GOAL FAILURE AND GOAL REVISION}

\section{Introduction}

Imagine you are sitting at home in front of your computer preparing for a difficult exam. You had planned to work a lot today but have eventually failed to achieve your goal. How do you feel and what do you do about it? Do you set yourself higher goals for the next study session to make up for what you have missed today? Or do you set yourself lower goals so that the goals are perhaps easier to achieve? These questions are important because they guide the decisions that are taken for the next study session.

The example above describes a typical situation that might occur during selfregulated learning. Self-regulated learning encompasses learners' abilities to set goals and to regulate thoughts, behaviors, and emotions to achieve those goals (Zimmerman, 2000). According to process models of self-regulated learning, learners set goals before studying. After studying, learners compare their actual learning outcome with their initial goals and evaluate whether they achieved their goals. Thereby, learners generate internal feedback about their goal achievement. This internal feedback is assumed to evoke achievement emotions, such as anger after goal failure or pride after goal success (Pekrun, 2006; Pekrun et al., 2002). Based on the internal feedback, learners revise their goals for the next study session. Hence, emotions and goal revision play a central role in self-regulated learning.

Self-regulated learning constitutes a key competence - especially when studying online (Broadbent, 2017). According to the novel, integrative $\mathrm{Cb}$-model (Sailer et al., this issue), self-regulated learning strategies enable learners to effectively use digital technologies to engage in various learning activities. That is, self-regulated learning strategies build the prerequisites for successful online learning. The number of online 


\section{EMOTIONS MEDIATE THE LINK BETWEEN GOAL FAILURE AND GOAL REVISION}

courses has increased during the recent COVID-19 pandemic (Sun et al., 2020). This increase will likely continue beyond the recent pandemic and engender profound and enduring changes in learning and teaching practices (Hofer et al., this issue). Online courses are flexible and convenient because students have the opportunity to study individually from home. Further, students can access learning materials via online learning platforms and can decide themselves where and when they want to study. However, this autonomy can be challenging because students have to deal with difficulties and goal failure on their own.

Dealing with goal failure and negative emotions in a constructive way is particularly important in times of crisis, which brings along additional self-regulation and emotional control demands (Brooks et al., 2020). That is, negative emotions after failing to achieve one's learning goal add to generally higher levels of tension and stress (Lee, 2020). In the long run, negative emotions and stress can have adverse effects on health and well-being (Böke et al., 2019; Watson \& Pennebaker, 1989). Thus, it is important to investigate how students emotionally react to and deal with goal failure in order to better support students while studying online - not exclusively, but especially - in times of crisis.

\subsection{How do students emotionally react to goal failure?}

Models of self-regulated learning suggest that goal failure triggers emotions. According to the cyclical process model of self-regulated learning (Zimmerman, 2000), learners set goals before learning and evaluate whether they achieved their goals after learning. This evaluation process evokes positive emotions in case of goal success and negative emotions in case of goal failure. The control-value theory of achievement emotions (Pekrun, 2006) specifies these assumptions. According to this theory, learners 


\section{EMOTIONS MEDIATE THE LINK BETWEEN GOAL FAILURE AND GOAL REVISION}

can experience various, distinct achievement emotions that are evoked by academic outcomes. Emotions thereby differ in valence (positive or negative) and activity level (activating or deactivating) (Pekrun et al., 2002). Positive activating emotions include pride and joy, and negative activating emotions include anger and tension. Positive deactivating emotions include relief and relaxation, and negative deactivating emotions include boredom and hopelessness. For instance, after goal failure, learners may report lower levels of joy, pride, or relaxation but higher levels of anger, tension, or hopelessness. Taken together, models of self-regulated learning suggest that goal failure can evoke a multitude of achievement emotions.

Empirical evidence supports the assumptions of the theoertical models. For instance, studies that experimentally manipulated goal failure in a task showed that goal failure was associated with more negative and less positive affect (Lebeau et al., 2018; Nummenmaa \& Niemi, 2004). In educational settings, goal failure has been linked to distinct achievement emotions that are evoked by academic outcomes (Pekrun, 2006; Pekrun et al., 2002). For instance, one study revealed that exam grades predict achievement emotions. A longitudinal study with school children revealed that end-ofyear math grades predicted math-related emotions in the subsequent school year (Pekrun et al., 2017): Poor math grades predicted higher anger and tension, and lower joy and pride. Another study assessed university students' emotions after they received their exam scores (Daniels \& Gierl, 2017). Students with poor exam scores reported lower pride and higher tension levels. In summary, these studies indicate that poor academic achievement is related to more negative and less positive emotions.

However, the studies cited above did not examine day-to-day variations in goal achievement and emotions. A daily assessment would allow to account for 


\section{EMOTIONS MEDIATE THE LINK BETWEEN GOAL FAILURE AND GOAL REVISION}

intraindividual variations in the link between goal achievement and emotions. Besides, previous studies focused on aggregated measures of goal achievement (i.e., exam scores) but did not test students' emotions after they failed to achieve their daily learning goals. It is thus unclear which achievement emotions are triggered by distinct events of goal failure.

\subsection{How do students revise their goals after goal failure?}

It is further unclear how learners exactly revise their goals after failure. One possibility is that learners down-regulate their goals for the next study session to avoid that they are failing again (downward goal revision). Downward goal revision means that learners lower their goals in a particular learning task from one study session to the next. Alternatively, learners might up-regulate their goals for the next study session to compensate for their previous goal failure (upward goal revision). Upward goal revision means that learners raise their goals in a particular learning task from one study session to the next. Hence, there are two conceivable ways of learners' goal revision after failure.

Empirical evidence on how students revise their goals after failure is scarce and inconclusive. Evidence for downward goal revision comes from sports psychology. One study revealed that that athletes who failed to achieve their self-set goals subsequently down-regulated their goals (Donovan \& Williams, 2003). It is, however, questionable whether students would down-regulate their goals after failure when preparing for a high-stakes exam when goal failure can have serious consequences. Moreover, other

evidence suggests that goal failure leads to upward regulatory processes, namely higher goal-directed effort (Fulford et al., 2010; Nelson et al., 2018). However, it is unclear whether this upward regulatory process also holds for goal revision. Furthermore, none 


\section{EMOTIONS MEDIATE THE LINK BETWEEN GOAL FAILURE AND GOAL REVISION}

of the abovementioned studies investigated the role of achievement emotions in goal revision. Taken together, research on the direction of goal revision after failure provided inconclusive results, and the role of achievement emotions in goal revision is unclear.

\subsection{The role of achievement emotions in goal revision}

Achievement emotions and self-regulation are intertwined. Anger, for instance, occurs if a desired goal is blocked (Carver \& Harmon-Jones, 2009), which is thought to motivate actions to overcome this blockage (Lench et al., 2016). Tension, as operationalized in this study, is most closely related to a feeling of anxiety (cf. Achievement Emotions Questionnaire (AEQ); Pekrun et al., 2011). Anxiety can increase effort investment to avoid future failure (Pekrun, 2006). Low levels of joy can promote the use of more rigid learning strategies and the reliance on external guidance (Pekrun et al., 2002). Pride constitutes a control-dependent emotion (Weiner, 1985). That is, learner who report low levels of pride after goal failure attribute their failure on internal, controllable reasons (Pekrun, 2006), which may promote subsequent self-regulation. Taken together, anger, tension, joy, and pride may stimulate self-regulation of learning processes. However, how exactly do these emotions relate to situations where learners fail to achieve their goal and are subsequently given the chance to revise their goal?

Emotions after goal failure could have a signaling function for goal revision. Emotions may signal a discrepancy between the goal and the learning outcome (Carver, 2015), and that negative emotions in particular stimulate regulation (Dignath et al., 2020; Inzlicht et al., 2015). Put differently, emotions may encourage learners to regulate their behavior to achieve a personal goal. This regulatory process could, for instance, refer to the revision of goals. This hypothesis is in line with models of self-regulated learning and emotions that assume that emotions stimulate regulatory processes from one study 


\section{EMOTIONS MEDIATE THE LINK BETWEEN GOAL FAILURE AND GOAL REVISION}

session to the next (Pekrun, 2006; Pekrun et al., 2002; Zimmerman, 2000). Taken together, emotions might signal a discrepancy between goals and learning outcomes which could in turn stimulate goal revision.

How could emotions after goal failure affect subsequent adaptations to goal pursuit? Previous empirical findings suggest that emotions encourage a compensatory mechanism after goal failure. For instance, students who reported more negative emotions on a particular day reported more goal-directed effort the next day (Seo \& Patall, 2020). The authors suggested that negative emotions signaled goal failure and students compensated for their goal failure by increasing goal-directed effort. Similarly, one study revealed that participants who were instructed to focus on their negative emotions after goal failure subsequently spent more time on a similar task compared to participants who focused on reasons for failure (Nelson et al., 2018). The authors interpreted time spent on task as a signal of increased effort and willingness to improve on past failure. Notably, the abovementioned studies focused on effort regulation but did not examine whether emotions promote goal revision. Hence, the proposed compensatory (or upward-regulatory) mechanism of emotions cannot be readily applied to goal revision.

Empirical evidence on the role of emotions for goal revision is scarce. One study tested whether participants' affect predicted their expected goal achievement over time (llies \& Judge, 2005). Participants were asked to estimate the number of words they thought they would be able to generate in a vocabulary task. After the task, participants received feedback on their goal achievement and had to report their expected goal achievement for the next trial. Results revealed that participants who received negative feedback on their goal failure reported more negative affect, and subsequently lowered 


\section{EMOTIONS MEDIATE THE LINK BETWEEN GOAL FAILURE AND GOAL REVISION}

(or down-regulated) their expectations. However, the study did not assess distinct achievement emotions and focused on the revision of expectancies rather than learning goals. Further, in this case, participants received external feedback on their goal achievement. It is thus unclear whether this downward regulatory process applies to educational settings where students set their own learning goals and self-evaluate their goal achievement.

\subsection{The present study}

Little is known about how students emotionally react to and deal with goal failure while studying online. Studies that tested students' affect after goal failure were not conducted in educational settings and did not assess distinct achievement emotions. Besides, previous research provided inconclusive results on the direction of goal revision after failure (downward or upward goal revision) and failed to account for the role of achievement emotions in this process. We thus addressed three research questions:

(1) How do students emotionally react to goal failure?

(2) How do students revise their goals after goal failure?

(3) Do students' achievement emotions after goal failure predict goal revision?

We tested our research questions in a sample of medical students who prepared for a high-stakes exam. We recruited this sample for two reasons. First, we were able to recruit a large sample of students who prepared for the same exam under comparable learning conditions, e.g., same time period and learning materials. Second, as students exclusively used the digital learning platform to prepare for the exam, we were able to track their study behavior using objective log-files.

Using an intensive longitudinal design, we investigated the dynamic within-person 


\section{EMOTIONS MEDIATE THE LINK BETWEEN GOAL FAILURE AND GOAL REVISION}

interplay between goal failure, achievement emotions, and goal revision. Over the course of 40 days, students set a learning goal each morning regarding the number of old exam questions they intended to answer on a given day. The actual number of old exam questions a student answered on a given day was assessed objectively via logfiles. Goal failure was conceptualized in two ways: (1) A dummy variable indicated whether a student answered fewer questions than intended (i.e., goal failure) and (2) a continuous variable indicated the absolute discrepancy between the learning goal and the actual number of questions in case of goal failure (i.e., goal discrepancy). The goal discrepancy variable thus quantified the severity of goal failure. Building on models of achievement emotions (Pekrun, 2006; Pekrun et al., 2002) and previous empirical findings (llies \& Judge, 2005), we hypothesized that a larger goal discrepancy after goal failure would predict more anger, more tension, less joy, and less pride.

Moreover, we tested whether goal discrepancy and students' emotions after goal failure on a particular day predicted goal revision for the next day. Building on models of self-regulation (e.g., Carver, 2015; Zimmerman, 2000), we expected that a discrepancy between the learning goal and the actual goal achievement would predict goal revision. Previous research, however, provided inconclusive results about the direction of this regulatory process. After goal failure, students may invest more effort to compensate for the previous failure (see Nelson et al., 2018; Seo \& Patall, 2020), e.g., by up-regulating goals. On the other hand, students may also lower their goals to arrive at a more realistic, achievable level (see llies \& Judge, 2005). Therefore, we did not a priori hypothesize a direction of this revision process (upward or downward goal revision). We expected negative emotions to mediate the link between goal discrepancy and goal revision. We build this hypothesis on the idea that negative emotions may have a 


\section{EMOTIONS MEDIATE THE LINK BETWEEN GOAL FAILURE AND GOAL REVISION}

signaling function after goal failure that stimulates regulation (Dignath et al., 2020;

Inzlicht et al., 2015). In other words, negative emotions should function as internal feedback that signals goal discrepancy, which should, in turn, boost goal revision.

\section{Methods}

\subsection{Participants}

We recruited medical students across Germany who used a web-based learning platform to prepare for their second state exam in October 2018. Students were invited via the platform's database. The present study was part of a larger project that tested the effectiveness of a self-regulation intervention (see [blinded] ${ }^{1}$ ). The self-regulation intervention was designed to improve students' goal achievement. Students in the intervention group received prompts to form an implementation intention on half of the days throughout the survey period. More specifically students were asked to internalize their study plan using the following instruction: "If I'm thinking about stopping to answer questions today, I will tell myself that I will continue answering questions until I have reached my intended workload!". We tested our hypotheses in the control group and validated our findings using data from the intervention group (see 2.3.1. for details on the cross-validation procedure).

Initially, 365 students registered for the study, and 352 of them used the learning platform and participated in the ambulatory assessment for at least one day. We excluded ambulatory assessment data if students failed to set a learning goal (exclusion of 50 observations). Moreover, we excluded three observations because students set unrealistically high learning goals ( $>4 S D$ above the average). Further, we excluded

\footnotetext{
${ }^{1}$ Additional information on the study procedures and questionnaires are available via the Open Science Framework and can be accessed at (https://osf.io/tg7zd/?view only=58ad6b4f10994f878625d713f2069a0c).
} 


\section{EMOTIONS MEDIATE THE LINK BETWEEN GOAL FAILURE AND GOAL REVISION}

data from days when students failed to answer the ambulatory assessment questionnaires (before and after studying) within 24 hours (exclusion of 675 observations). In these cases, a meaningful interpretation of the ambulatory data would not have been possible. The final sample comprised 344 students $\left(71 \%\right.$ female, $M_{\text {age }}=$ 26.00 years, $S D_{\text {Age }}=3.57$ ). The control group comprised 114 students (with a total of 3235 measurement occasions), and the intervention group comprised 230 students (with a total of 6389 measurement occasions).

Ethics approval was obtained from the ethics committee of [blinded]. Prior to testing, all participants gave written informed consent. Participants were paid 1 Euro for each day with complete data and received a bonus of 10 Euro if they had provided complete data for at least 30 days.

\subsection{Procedure: Ambulatory assessment and measures}

Students prepared for a high-stakes exam using a digital learning platform (www.amboss.com). Over the course of 40 days, participants answered daily digital preand post-learning questionnaires. Participants received e-mail invitations to fill in the prelearning and post-learning questionnaire, respectively. Below, we outline the variables that we used in the present study. A detailed overview of the ambulatory assessment procedure and variables assessed in the pre- and post-learning questionnaire can be found in [blinded].

\subsubsection{Learning goal}

In the pre-learning questionnaire, i.e., before learning, students were prompted to set a learning goal. The learning goal entailed the number of old exam questions (multiple-choice questions) a student intended to answer on a given day. The average learning goal across all participants was $92.23(S D=44.6)$. By comparison, during the 


\section{EMOTIONS MEDIATE THE LINK BETWEEN GOAL FAILURE AND GOAL REVISION}

actual exam students have to answer 160 questions within four hours. Answering old exam questions constituted the main learning activity on the learning platform. Students were asked to indicate how many questions they want to answer on that day and typed their learning goal into an open text field.

\subsubsection{Achievement emotions}

In the post-learning questionnaire, i.e., after learning, students reported their achievement emotions after learning. Students reported on a 5-point Likert scale to what extend they feel angry, tense, joyful, and proud after learning ("Please indicate how you feel right now, after learning"; 1 = "strongly disagree"; 5 = "strongly agree").

\subsubsection{Daily goal failure and goal discrepancy}

We generated a dummy-variable that indicated goal failure. To do so, we computed the difference between the number of old exam questions answered on a given day (assessed via log-files) and the learning goal (see 2.2.1). Negative values indicated goal failure, i.e., students' actual number of old exam questions was lower than their learning goal. A value of zero or positive values indicated goal success, i.e., students answered as many old exam questions as intended or answered more questions than intended. A dummy variable coded the former case as 1 and the latter case as zero. We further generated a dummy-like variable indicating goal discrepancy. This variable depicted the absolute discrepancy between the learning goal and the actual number of answered questions in case of goal failure, and took the value zero in case of goal success. The goal discrepancy variable served to quantify the severity of goal failure. 


\section{EMOTIONS MEDIATE THE LINK BETWEEN GOAL FAILURE AND GOAL REVISION}

\subsubsection{Goal revision}

We operationalized goal revision as the difference between next day's learning goal and the current learning goal. That is, positive values indicated that students upregulated their goal the next day compared to the given day. Negative values indicated that students down-regulated their goal the next day compared to the given day.

\subsection{Data analyses}

All analyses were carried out using R (R Core Team, 2019) and Mplus (Muthén \& Muthén, 2017). Significance levels were set at 0.05 throughout the analyses. First, we conducted multilevel analyses (days clustered in students) to test whether daily goal failure predicted anger, tension, joy, and pride. As predictor, we included goal discrepancy (person-mean centered) to test whether the severity of goal failure predicted students' emotions.

Second, we conducted within-subject path analyses in Mplus. Thereby, we tested whether goal discrepancy and emotions after goal failure predicted goal revision the next day. Further, we tested whether the link between goal discrepancy and goal revision was mediated via achievement emotions. To calculate the indirect effect, we followed the guidelines for within-person mediation analysis provided by Preacher et al. (2010). We regressed emotions on goal discrepancy (path a) and regressed goal revision on emotions (path b). We then multiplied the regression weights from path $a$ and path $b$ and calculated confidence intervals around the indirect effect to test whether the indirect effect is significant. We only included consecutive days in this analysis. This means that we excluded observations where the time gap between the post-learning questionnaire and the consecutive pre-learning questionnaire exceeded 24 hours (exclusion of 1331 observations). These cases would have been difficult to interpret because we do not 


\section{EMOTIONS MEDIATE THE LINK BETWEEN GOAL FAILURE AND GOAL REVISION}

know whether students studied in between. Further, we excluded observations where the time gap between the post-learning questionnaire and the consecutive pre-learning questionnaire was shorter than 1 hour (exclusion of 121 observations). In these cases, students likely answered the post-learning questionnaire retrospectively. Moreover, we tested these models for each emotion separately (anger, tension, joy, and pride) because within-person correlations among the two positively coded and the two negatively coded emotions were high (see Table 1).

\subsubsection{Group comparisons and cross-validation of findings}

We compared students from the control and intervention group regarding our main variables. Groups were comparable regarding their average goal setting ( $t(344.88)$ $=-.17, p=.863)$ and regarding the average number of questions answered per day over the survey period $(t(343.55)=-.54, p=.587)$. Groups did not differ with respect to average-reported anger $(t(339.79)=-.10, p=.924)$, tension $(t(337.71)=.17, p=.864)$, joy $(t(343.40)=-1.30, p=.196)$, nor pride $(t(343.76)=-.43, p=.671)$. Groups were comparable regarding their average rate of goal failure over the survey period $(z(344)=$ $.582, p=.561)$. However, within the intervention group, students were more likely to achieve their goal if they had been prompted to form an implementation intention $(z(230)$ $=2.99, p=.003$, see [blinded] $)$. Therefore, we added a dummy variable that indicated the intervention days in the analyses in the intervention group.

We used cross-validation to ensure the robustness of our model results and to prevent overfitting. A major advantage of cross-validation is that it counteracts some biases in analysis strategies, such as p-hacking or procedural overfitting, i.e., choosing analysis strategies based on which strategies fit the data best (for a recent discussion of the advantages of cross-validation in psychological research see Yarkoni \& Westfall, 


\section{EMOTIONS MEDIATE THE LINK BETWEEN GOAL FAILURE AND GOAL REVISION}

2017).

In this study, we chose a replication approach to test whether the pattern of results observed in the control group would hold for the intervention group. To do so, we first used the control group as a training (or "try out") sample and decided about the data exclusion criteria and exact data analysis strategy. Only after we had decided on a procedure did we analyze the data of the intervention group, using the data analysis strategies that we had fixed beforehand. That is, the intervention group served as a test (or "hold out") sample. In the test sample, we thus minimized any bias in the choice of data analyses procedures. In the following, we therefore focus on the results for the intervention group.

We successfully replicated the findings from the control group (the training sample) in the intervention group (the test sample). The small discrepancies between the groups are described at the end of the respective results sections (see 3.2., 3.3.). Detailed results from the analyses in the control group are reported in the supplementary materials.

\section{Results}

\subsection{Descriptive statistics}

Average goal failure was low over the survey period meaning that students achieved their goal most of the time (see Table 1). Students' average learning goal (see Table 1) was higher than their average number of questions answered per day ( $M=$ $90.52, S D=61.49)$. On goal failure days, students' average learning goal was 107.44 $(S D=57.41)$. That is, given the average number of questions answered per day, students' goal setting on goal failure days was still within a realistic range. The average 
EMOTIONS MEDIATE THE LINK BETWEEN GOAL FAILURE AND GOAL REVISION

goal discrepancy on goal failure days was $49.13(S D=42.61$, range $[1 ; 308])$. That is, in case of failure, students missed their goal by about 49 questions.

Analyses of the intraclass coefficients (ICC) indicated substantial within-person variability of all variables over time. Within-person correlation analyses revealed that goal failure was associated with more anger, more tension, less joy, and less pride.

Table 1

Descriptive statistics

\begin{tabular}{|c|c|c|c|c|c|c|c|c|c|}
\hline & & $\begin{array}{l}\text { Mean } \\
(S D)\end{array}$ & ICC & 1 & 2 & 3 & 4 & 5 & 6 \\
\hline 1 & $\begin{array}{l}\text { Goal failure } \\
(\%)\end{array}$ & $\begin{array}{c}.33 \\
(.24)\end{array}$ & .23 & & & & & & \\
\hline 2 & $\begin{array}{l}\text { Goal } \\
\text { discrepancy }\end{array}$ & $\begin{array}{r}16.19 \\
(33.63)\end{array}$ & .31 & $.64^{* * *}$ & & & & & \\
\hline 3 & $\begin{array}{l}\text { Learning } \\
\text { goal }\end{array}$ & $\begin{array}{r}92.26 \\
(30.66)\end{array}$ & .42 & $.18^{\star \star \star}$ & $.32^{\star \star \star}$ & & & & \\
\hline 4 & Anger & $\begin{array}{l}2.04 \\
(.77)\end{array}$ & .34 & $.14^{\star \star *}$ & $.17^{\star \star \star}$ & .01 & & & \\
\hline 5 & Tension & $\begin{array}{l}1.96 \\
(.93)\end{array}$ & .53 & $.08^{* * *}$ & $.10^{\star \star * *}$ & .01 & $.50^{* \star *}$ & & \\
\hline 6 & Joy & $\begin{array}{l}2.85 \\
(.80)\end{array}$ & .40 & $-.16^{\star * \star}$ & $-.16^{\star * \star}$ & $.03^{*}$ & $-.46^{\star \star \star}$ & $-.35^{\star \star \star}$ & \\
\hline 7 & Pride & $\begin{array}{l}2.75 \\
(.78)\end{array}$ & .39 & $-.23^{\star \star \star}$ & $-.24^{\star * *}$ & $.05^{* * *}$ & $-.49^{\star \star \star}$ & $-.32^{\star \star \star}$ & $.65^{\star \star \star}$ \\
\hline
\end{tabular}

Note. $N=230, k=6389$. Correlations are within-person.

${ }^{*} p<.05,{ }^{* *} p<.01,{ }^{* * *} p<.001$

\subsection{Goal discrepancy as predictor of daily emotions}

To answer the first research question, we tested whether goal discrepancy predicted daily achievement emotions. Results revealed that a higher goal discrepancy 


\section{EMOTIONS MEDIATE THE LINK BETWEEN GOAL FAILURE AND GOAL REVISION}

predicted more anger, more tension, less joy, and less pride (see Table 2). In other words, the more students missed their goal, the stronger their emotions (see Figure 1).

Together, these results suggest that a discrepancy between intended and actual learning outcome determines students' achievement emotions.

Table 2

Results of the multilevel regression analyses predicting emotions by daily goal discrepancy

\begin{tabular}{lcccc}
\hline & Anger & Tension & Joy & Pride \\
\cline { 2 - 5 } & \multicolumn{4}{c}{ Estimates [Cl] } \\
\cline { 2 - 5 } (Intercept) & $1.96^{* * *}$ & $1.93^{* * *}$ & $2.93^{* * *}$ & $2.84^{* * *}$ \\
Goal & {$[1.86-2.06]$} & {$[1.81-2.05]$} & {$[2.82-3.04]$} & {$[2.73-2.95]$} \\
discrepancy & $.13^{* * *}$ & $.07^{\star * *}$ & $-.12^{* * *}$ & $-.19^{* \star *}$ \\
$R^{2}$ & {$[.11-.15]$} & {$[.05-.08]$} & {$[-.14--.10]$} & {$[-.21--.12]$} \\
& .018 & .004 & .015 & .035 \\
\hline
\end{tabular}

Note. $N=230, k=6389$. Estimates are standardized.

${ }^{*} p<.05,{ }^{* *} p<.01,{ }^{* * *} p<.001$

These results from the test sample (intervention group) replicated the results that we obtained from the analyses in the training sample (control group; see Table S2 and Figure S1). 

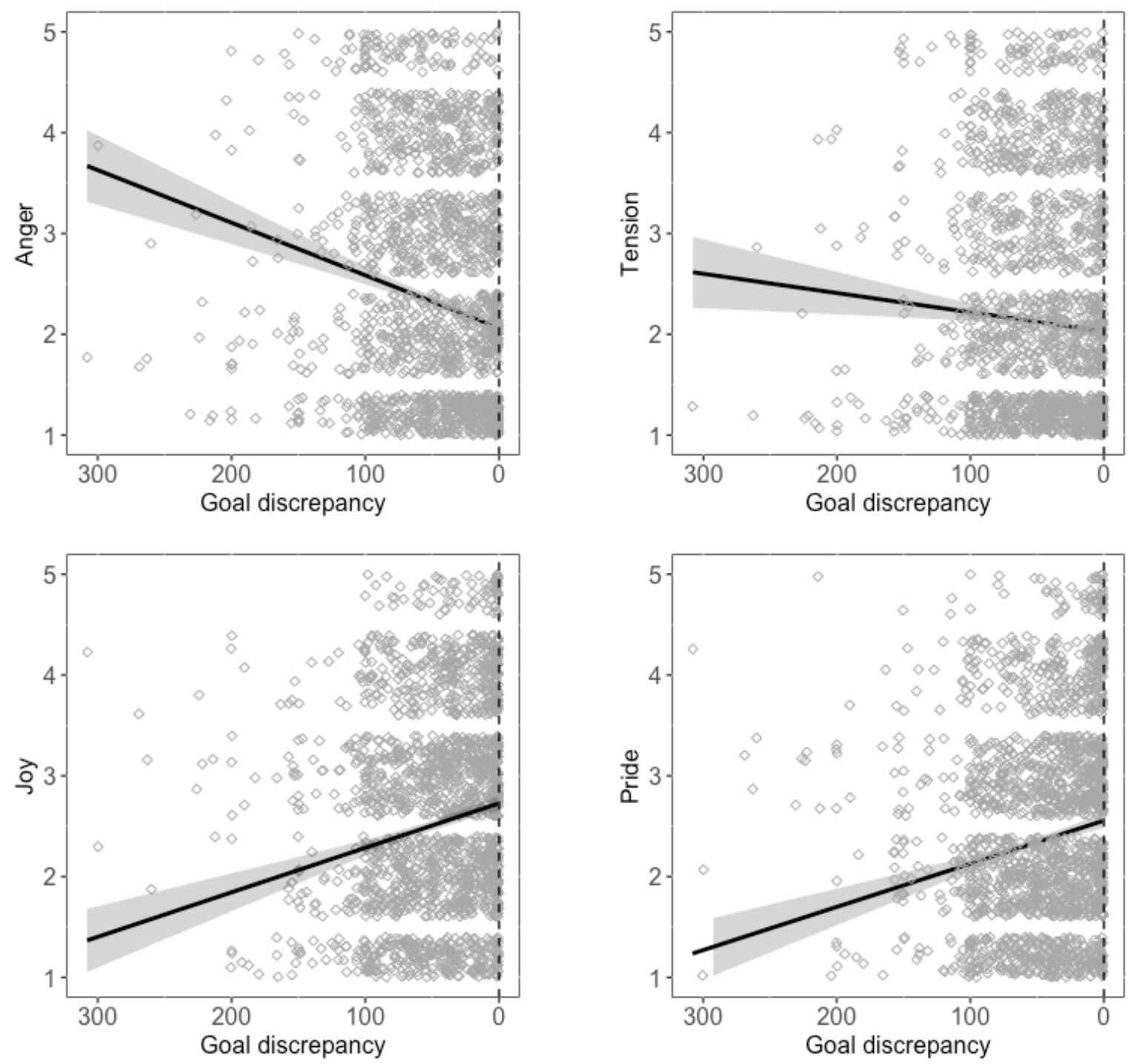

Figure 1. Achievement emotions after goal failure. Goal discrepancy (x-axis) depicts the discrepancy between the intended learning goal and the actual number of answered old exam questions on a given day. After goal failure, a larger discrepancy between the learning goal and the actual number of questions predicted more anger, more tension, less joy, and less pride.

\subsection{Goal discrepancy and emotions after goal failure as predictors of goal revision}

To answer our second research question, we tested whether goal discrepancy predicted goal revision the next day. After goal failure, students lowered their goal on 


\section{EMOTIONS MEDIATE THE LINK BETWEEN GOAL FAILURE AND GOAL REVISION}

average by about three questions $(M=-3.39, S D=(48.96)$. Results of the regression analyses revealed that, irrespective of students' emotions, a larger goal discrepancy predicted stronger goal revision (see Figure 2) ${ }^{2}$. After goal failure, a larger goal discrepancy predicted a down-regulation of goals the next day compared to the current day. In other words, students set less ambitious goals the next day the more severely they fell short of achieving their goal. Hence, students adaptively revised their goals based on goal discrepancy.

To answer our third research question, we tested whether students' achievement emotions after goal failure predicted goal revision. Results revealed that negative emotions (anger and tension) predicted goal revision after goal failure (see Figure 2). In other words, if students reported more anger and more tension after goal failure on a given day (compared to their personal average), they set themselves higher goals the next day. Results further revealed that following days when students reported more joy and more pride (compared to their personal average), they set themselves lower goals the next day.

Building on these findings, we further tested whether achievement emotions mediated the link between goal discrepancy and subsequent goal revision. That is, we focused on goal failure days and tested the indirect path from goal discrepancy to goal revision the next day through achievement emotions. Results revealed that goal discrepancy predicted subsequent goal revision indirectly via anger $(\beta=.011$, [.002$.020], p=.014)$, joy $(\beta=.020,[.008-.032], p=.001)$, and pride $(\beta=.035,[.019-.051]$, $p<.001)$, but not via tension $(\beta=.005,[-.001-.012], p=.090)$. In other words, goal

\footnotetext{
2 We further tested whether the percentage of correctly solved questions predicted goal revision, which was not the case $(\beta=-.01 ; \mathrm{Cl}[-.04 ; .01] ; p=.280)$.
} 


\section{EMOTIONS MEDIATE THE LINK BETWEEN GOAL FAILURE AND GOAL REVISION}

discrepancy predicted more anger, less joy, and less pride which, in turn, predicted an upward regulation of goals the next day (see Figure 2).
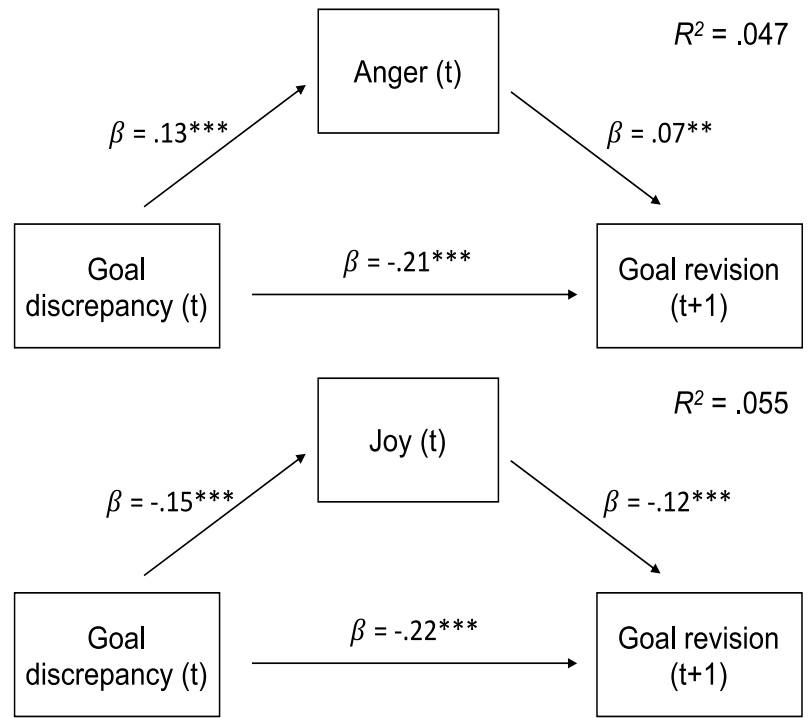
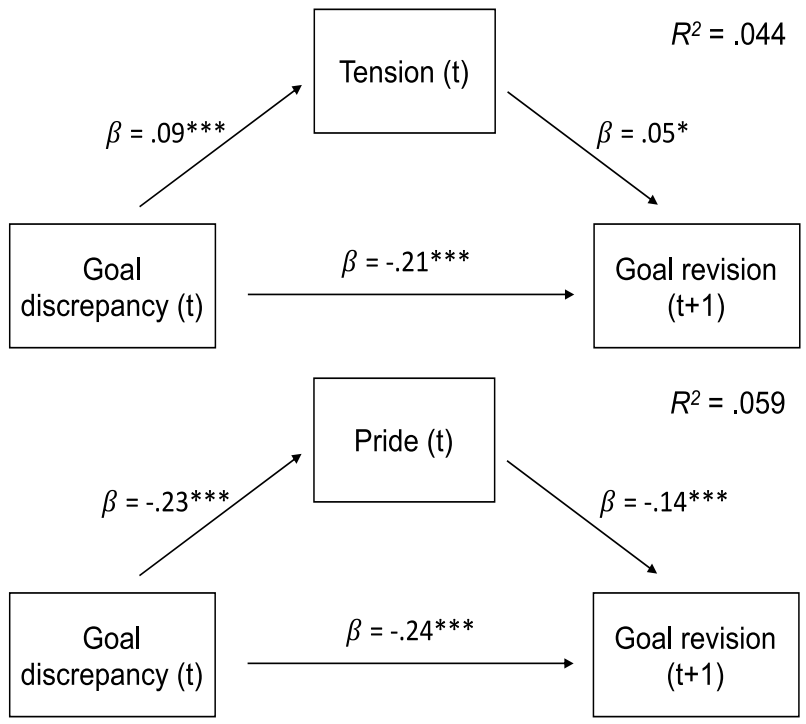

Figure 2. Within-person path analyses. After goal failure on day (t), goal discrepancy predicted subsequent goal revision on day $(t+1)$ indirectly via anger, joy, pride, but not via tension. $R^{2}$ refers to the explained within-person variance in goal revision. ${ }^{*} p<.05,{ }^{* *} p<.01,{ }^{* * *} p<.001$

In sum, this pattern of results indicates that achievement emotions after goal failure mediate the link between goal discrepancy and subsequent goal revision. After goal failure, goal discrepancy predicted a downward regulation of goals. In contrast, high levels of anger, low levels of joy, and low levels of pride after goal failure predicted an upward regulation of goals. In other words, after goal failure, a larger goal discrepancy predicted downward goal revision but negative emotions reduced this downward regulatory process. Negative emotions might thus encourage students to set more ambitious goals to compensate for previous goal failure and, thereby, attenuate the general downward goal revision process after goal failure.

Besides slight differences in beta weights, these results replicated the results that 


\section{EMOTIONS MEDIATE THE LINK BETWEEN GOAL FAILURE AND GOAL REVISION}

we obtained from the analyses in the training sample (the control group; see Figure S2).

\section{Discussion}

We tested the role of goal failure and achievement emotions in dynamic goal revision. Results revealed that students reported more anger, more tension, less joy, and less pride the more they missed their goal. After goal failure, students generally down-regulated their goal the next day, and even more so the farther they missed their goal. Achievement emotions mediated this link, however. If students reported stronger negative emotions (i.e., more anger, less joy, and less pride) after goal failure, they lowered their goals to a lesser extent the next day. The robustness of these findings was demonstrated using cross-validation. Together, results suggest that goal revision is determined by previous goal failure, but also by students' achievement emotions after goal failure.

\subsection{Goal failure and goal discrepancy predict achievement emotions}

Findings suggest that goal failure triggers negative emotions and dampens positive emotions. Note that students in this study were prompted to set a learning goal each day. Hence, our findings apply to situations where students set a learning goal and failed to achieve this goal. Importantly, students did not receive external feedback on

their goal failure or success. Rather, students self-monitored their goal achievement and generated internal feedback about their daily goal achievement. This internally generated feedback, in turn, predicted students' achievement emotions. These findings support process models of self-regulated learning (e.g., Zimmerman, 2000) that assume that learners continually self-monitor and self-evaluate their goal achievement.

Our findings further suggest that achievement emotions are evoked by a discrepancy between the goal and the actual learning outcome. After goal failure, a 


\section{EMOTIONS MEDIATE THE LINK BETWEEN GOAL FAILURE AND GOAL REVISION}

larger goal discrepancy predicted more anger, more tension, less joy, and less pride. In other words, the more students failed to reach their goal, the stronger their emotions. Hence, students' achievement emotions seem to depend on the extent of goal failure.

\subsection{Goal discrepancy and achievement emotions predict goal revision}

Previous research provided inconclusive results on how exactly students revise their goals after failure. Our findings argue in favor of downward goal revision after goal failure, which is in line with previous research (Donovan \& Williams, 2003; llies \& Judge, 2005). Students down-regulated their goals after goal failure, particularly if they widely missed their goal. In this case, students might have realized that their goal was too ambitious and decided to lower their learning goal. On the one hand, this downward goal revision after failure is adaptive as students probably set more realistic goals. Taken to the extreme, however, this would imply that students down-regulate their goals to a minimum level to guarantee goal achievement.

Students' negative emotions after goal failure likely counteract this downward trend observable between goal failure and goal revision. If students reported more negative emotions after failure, they regulated their goals upward (instead of downward) the next day. Negative emotions after failure might be viewed as an internal feedback signal that calls for regulatory action (Carver, 2015; Dignath et al., 2020; Inzlicht et al., 2015). That is, negative emotions (more anger, less joy, and less pride) encourage students to compensate for previous failure by up-regulating their goals. This interpretation supports previous research in the field of effort regulation that suggested a compensatory mechanism of emotions after goal failure (Nelson et al., 2018; Seo \& Patall, 2020). In sum, our results suggest that negative emotions function as an internal feedback signal that promotes upward goal revision after failure. 


\section{EMOTIONS MEDIATE THE LINK BETWEEN GOAL FAILURE AND GOAL REVISION}

Notably, we focused on activating emotions in this study (joy, pride, anger, and tension). Hence, it is unclear whether the proposed compensatory mechanism holds for deactivating emotions as well (e.g., hopelessness or relief). From a motivational perspective, activating and deactivating emotions may relate to different behavioral tendencies, i.e., approach and avoidance (Carver, 2006). That is, negative activating emotions may motivate approach-related action, e.g., increased effort investment. Negative deactivating emotions may motivate avoidance-related action, e.g., withdrawal from the intended course of action. Applied to goal regulation, one could hypothesize that activating emotions encourage an up-regulation of goals while deactivating emotions encourage a down-regulation of goals. Hence, future research could test the role of negative, deactivating emotions for goal revision such as hopelessness.

Taken together, we found evidence for both upward and downward goal revision after failure. Students generally down-regulated their goals after failure. However, this downward revision was attenuated by students' negative emotions. Results of the present study provide insights on the dynamic, within-person interplay between goal failure, achievement emotions, and subsequent goal revision. Our findings thus contribute to a better understanding on how students revise their learning goals after goal failure, and unveil the importance of achievement emotions in this process.

\subsection{Limitations and future directions}

The study has several limitations. First, the study was conducted in a selective sample of high-achieving medical students who prepared for a high-stakes exam. Hence, our sample comprised students with above-average cognitive abilities who were highly motivated to perform well. Accordingly, goal failure was relatively low over the survey period. Goal failure might be more prevalent among less capable students with 


\section{EMOTIONS MEDIATE THE LINK BETWEEN GOAL FAILURE AND GOAL REVISION}

poorer self-regulation strategies. Therefore, future studies should test the effects of goal failure on achievement emotions and goal revision in more diverse samples.

Second, we did not experimentally manipulate goal failure. Instead, we investigated the role of goal failure and emotions in an authentic, educational setting. In this setting, it would have been unethical to experimentally manipulate goal failure because students were preparing for an important exam. Future studies could experimentally manipulate goal failure in a less important task to test the causal chain between goal failure, achievement emotions, and subsequent goal revision.

Third, we focused on goal failure as a predictor of achievement emotions. Goal failure denoted a discrepancy between a quantitative learning goal and the actual number of questions answered on a given day. Future studies could test how achieving a qualitative learning goal, e.g., mastering a specific learning content, predicts achievement emotions and goal revision. In this study, the percentage of correctly solved questions did not predict goal revision, maybe because students set quantitative and not qualitative learning goals. Further, achievement emotions are possibly determined by additional variables such as motivational variables. For instance, it has been shown that subjective control over a task and subjective value of a task predict achievement emotions (Pekrun, 2006; Pekrun et al., 2002). It is plausible to assume that control and value beliefs also affect achievement emotions after learning and, possibly, subsequent goal revision. Therefore, future research should account for students' control and value beliefs when predicting students' achievement emotions and goal revision after failure.

Finally, we analyzed data from two different groups and one of the groups was part of an intervention study. There were no major differences across groups regarding 


\section{EMOTIONS MEDIATE THE LINK BETWEEN GOAL FAILURE AND GOAL REVISION}

our central variables, e.g., average reported anger, tension, joy, and pride, nor average goal failure across the survey period. However, we cannot fully rule out that the intervention caused the small differences in effect sizes observed across groups. Still, in terms of statistical significance, the cross-validation yielded highly similar results for both groups. That is, the relations between goal failure, achievement emotions, and goal revision remained significant in spite of an experimental manipulation that affected goal achievement. Therefore, we are convinced that the conclusions that we drew from our results are robust and generalizable over different contexts.

\subsection{Practical implications}

We found that goal failure predicted negative emotions. In times of crisis, goal failure thus constitutes an additional emotional burden that adds to generally increased levels of stress (Brooks et al., 2020; Lee, 2020). Hence, our findings highlight the importance of developing effective interventions to avoid goal failure or to deal with goal failure adaptively.

Self-regulated learning interventions could help students to improve their goal setting and goal achievement. For instance, one study revealed that daily implementation intentions enhance the likelihood of goal attainment (see [blinded]). Hence, self-regulated learning interventions could be offered alongside the online course or could be embedded in the learning management system. Interventions should include strategies that help students to set realistic, yet ambitious goals.

On the downside, it is hardly possible to avoid goal failure entirely, and potentially it is even detrimental. Failure can benefit learning, but only if students see their personal failure as an opportunity to improve their knowledge or skills (Eskreis-Winkler \& Fishbach, 2019). For instance, research on productive failure revealed that failing to 


\section{EMOTIONS MEDIATE THE LINK BETWEEN GOAL FAILURE AND GOAL REVISION}

solve an ill-structured problem can benefit subsequent problem-solving in a wellstructured task (e.g., Kapur, 2008). University teachers should thus foster positive beliefs about failure which could help students to adaptively deal with failure during academic learning.

\subsection{Conclusion}

Imagine the exemplary situation at the beginning: You are preparing for an exam and you are setting yourself ambitious goals. In the evening, you compare your goals to your learning outcome and realize that you missed your goal that day. How do you feel? Findings from our study offer a differentiated picture: You will probably feel angry, a bit tense, less joyful, and less proud, and the more so the farther away from your goal you were. Emotions after failure thus signal the discrepancy between your initial goal and your actual learning outcome. How do you revise your goal after failure? Results suggest that you probably down-regulate your goal - especially if you have widely missed your goal. By doing so, you might increase the likelihood of achieving your goal next time. However, taken to the extreme, this would imply that you lower your learning goal to a minimum level to make sure that you will certainly reach the goal. Negative (and fewer positive) emotions after failure encourage a compensatory mechanism. That is, if you widely miss your goal, negative emotions signal the need to improve. In these cases, you will probably down-regulate your goals to a lesser degree. Therefore, adaptive goal revision depends on the severity of goal failure but also on the emotional response to goal failure.

\section{Open practices statement}

The data and the script that was used to analyze the data are available via the Open Science Framework and can be accessed at 


\section{EMOTIONS MEDIATE THE LINK BETWEEN GOAL FAILURE AND GOAL REVISION}

(https://osf.io/2z7mp/?view only=31df1dd5d39c4fd5863fbd1e33ffd228). Additional information on the study procedures and questionnaires are available via the Open

Science Framework and can be accessed at

(https://osf.io/tg7zd/?view only=58ad6b4f10994f878625d713f2069a0c).

\section{References}

Böke, B. N., Mills, D. J., Mettler, J., \& Heath, N. L. (2019). Stress and coping patterns of university students. Journal of College Student Development, 60(1), 85-103. https://doi.org/10.1353/csd.2019.0005

Broadbent, J. (2017). Comparing online and blended learner's self-regulated learning strategies and academic performance. The Internet and Higher Education, 33, 2432. https://doi.org/10.1016/j.iheduc.2017.01.004

Brooks, S. K., Webster, R. K., Smith, L. E., Woodland, L., Wessely, S., Greenberg, N., \& Rubin, G. J. (2020). The psychological impact of quarantine and how to reduce it: rapid review of the evidence. The Lancet, 395(10227), 912-920. https://doi.org/10.1016/S0140-6736(20)30460-8

Carver, C. S. (2006). Approach, avoidance, and the self-regulation of affect and action. Motivation and Emotion, 30(2), 105-110. https://doi.org/10.1007/s11031-006-90447

Carver, C. S. (2015). Control processes, priority management, and affective dynamics. Emotion Review, 7(4), 301-307. https://doi.org/10.1177/1754073915590616

Carver, C. S., \& Harmon-Jones, E. (2009). Anger is an approach-related affect: Evidence and implications. Psychological Bulletin, 135(2), 183-204. https://doi.org/10.1037/a0013965 


\section{EMOTIONS MEDIATE THE LINK BETWEEN GOAL FAILURE AND GOAL REVISION}

Daniels, L. M., \& Gierl, M. J. (2017). The impact of immediate test score reporting on university students' achievement emotions in the context of computer-based multiple-choice exams. Learning and Instruction, 52, 27-35.

https://doi.org/10.1016/j.learninstruc.2017.04.001

Dignath, D., Eder, A. B., Steinhauser, M., \& Kiesel, A. (2020). Conflict monitoring and the affective-signaling hypothesis-An integrative review. Psychonomic Bulletin and Review, 27(2), 193-216. https://doi.org/10.3758/s13423-019-01668-9

Donovan, J. J., \& Williams, K. J. (2003). Missing the mark: Effects of time and causal attributions on goal revision in response to goal-performance discrepancies. Journal of Applied Psychology, 88(3), 379-390. https://doi.org/10.1037/0021-9010.88.3.379

Eskreis-Winkler, L., \& Fishbach, A. (2019). Not learning from failure-the greatest failure of all. Psychological Science, 30(12), 1733-1744. https://doi.org/10.1177/0956797619881133

Fulford, D., Johnson, S. L., Llabre, M. M., \& Carver, C. S. (2010). Pushing and coasting in dynamic goal pursuit. Psychological Science, 21(7), 1021-1027. https://doi.org/10.1177/0956797610373372

Ilies, R., \& Judge, T. A. (2005). Goal regulation across time: The effects of feedback and affect. Journal of Applied Psychology, 90(3), 453-467. https://doi.org/10.1037/00219010.90 .3 .453

Inzlicht, M., Bartholow, B. D., \& Hirsh, J. B. (2015). Emotional foundations of cognitive control. Trends in Cognitive Sciences, 19(3), 126-132. https://doi.org/10.1016/j.tics.2015.01.004

Kapur, M. (2008). Productive Failure. Cognition and Instruction, 26(3), 379-424. https://doi.org/10.1080/07370000802212669 
EMOTIONS MEDIATE THE LINK BETWEEN GOAL FAILURE AND GOAL REVISION

Lebeau, J. C., Gatten, H., Perry, I., Wang, Y., Sung, S., \& Tenenbaum, G. (2018). Is failing the key to success? A randomized experiment investigating goal attainment effects on cognitions, emotions, and subsequent performance. Psychology of Sport and Exercise, 38, 1-9. https://doi.org/10.1016/j.psychsport.2018.05.005

Lee, J. (2020). Mental health effects of school closures during COVID-19. The Lancet Child \& Adolescent Health, 4(6), 421. https://doi.org/10.1016/S23524642(20)30109-7

Lench, H. C., Tibbett, T. P., \& Bench, S. W. (2016). Exploring the toolkit of emotion: What do sadness and anger do for us? Social and Personality Psychology Compass, 10(1), 11-25. https://doi.org/10.1111/spc3.12229

Muthén, L. K., \& Muthén, B. O. (2017). Mplus User’s Guide. Eighth Edition. Muthén \& Muthén.

Nelson, N., Malkoc, S. A., \& Shiv, B. (2018). Emotions know best: The advantage of emotional versus cognitive responses to failure. Journal of Behavioral Decision Making, 31(1), 40-51. https://doi.org/10.1002/bdm.2042

Nummenmaa, L., \& Niemi, P. (2004). Inducing affective states with success-failure manipulations: A meta-analysis. Emotion, 4(2), 207-214. https://doi.org/10.1037/1528-3542.4.2.207

Pekrun, R. (2006). The control-value theory of achievement emotions: Assumptions, corollaries, and implications for educational research and practice. Educational Psychology Review, 18(4), 315-341. https://doi.org/10.1007/s10648-006-9029-9 
Pekrun, R., Goetz, T., Frenzel, A. C., Barchfeld, P., \& Perry, R. P. (2011). Measuring emotions in students' learning and performance: The Achievement Emotions Questionnaire (AEQ). Contemporary Educational Psychology, 36(1), 36-48. https://doi.org/10.1016/j.cedpsych.2010.10.002

Pekrun, R., Goetz, T., Titz, W., \& Perry, R. P. (2002). Academic emotions in students' self-regulated learning and achievement: A program of qualitative and quantitative research. Educational Psychologist, 37(2), 91-105.

https://doi.org/10.1207/S15326985EP3702_4

Pekrun, R., Lichtenfeld, S., Marsh, H. W., Murayama, K., \& Goetz, T. (2017).

Achievement emotions and academic performance: Longitudinal models of reciprocal effects. Child Development, 88(5), 1653-1670.

https://doi.org/10.1111/cdev.12704

Preacher, K. J., Zyphur, M. J., \& Zhang, Z. (2010). A general multilevel SEM framework for assessing multilevel mediation. Psychological Methods, 15(3), 209-233. https://doi.org/10.1037/a0020141

R Core Team. (2019). R: A language and environment for statistical computing. R Foundation for Statistical Computing.

Seo, E., \& Patall, E. A. (2020). Feeling proud today may lead people to coast tomorrow: Daily intraindividual associations between emotion and effort in academic goal striving. Emotion, 1-19. https://doi.org/10.1037/emo0000752

Sun, L., Tang, Y., \& Zuo, W. (2020). Coronavirus pushes education online. Nature Materials, 19(6), 687-687. https://doi.org/10.1038/s41563-020-0678-8 
EMOTIONS MEDIATE THE LINK BETWEEN GOAL FAILURE AND GOAL REVISION

Watson, D., \& Pennebaker, J. W. (1989). Health complaints, stress, and distress:

Exploring the central role of negative affectivity. Psychological Review, 96(2), 234254. https://doi.org/10.1037/0033-295X.96.2.234

Weiner, B. (1985). An Attributional Theory of Achievement Motivation and Emotion. Psychological Review, 92(4), 548-573. https://doi.org/10.1037/0033-295X.92.4.548

Yarkoni, T., \& Westfall, J. (2017). Choosing prediction over explanation in psychology: Lessons from machine learning. Perspectives on Psychological Science, 12(6), 1100-1122. https://doi.org/10.1177/1745691617693393

Zimmerman, B. J. (2000). Attaining self-regulation: A social cognitive perspective. In M. Boekaerts, P. R. Pintrich, \& M. Zeidner (Eds.), Handbook of self-regulation (p. 1339). Academic Press. https://doi.org/10.1016/B978-012109890-2/50031-7 
EMOTIONS MEDIATE THE LINK BETWEEN GOAL FAILURE AND GOAL REVISION

\section{Supplementary materials}

Table S1

Descriptive statistics (control group)

\begin{tabular}{|c|c|c|c|c|c|c|c|c|c|}
\hline & & $\begin{array}{l}\text { Mean } \\
(S D)\end{array}$ & ICC & 1 & 2 & 3 & 4 & 5 & 6 \\
\hline 1 & $\begin{array}{l}\text { Goal failure } \\
(\%)\end{array}$ & $\begin{array}{c}.33 \\
(.27)\end{array}$ & .27 & & & & & & \\
\hline 2 & $\begin{array}{l}\text { Goal } \\
\text { discrepancy }\end{array}$ & $\begin{array}{c}15.31 \\
(31.16)\end{array}$ & .26 & $.67^{\star \star \star}$ & & & & & \\
\hline 3 & $\begin{array}{l}\text { Learning } \\
\text { goal }\end{array}$ & $\begin{array}{l}92.29 \\
(23.04)\end{array}$ & .29 & $.21^{\star \star \star}$ & $.33^{\star * *}$ & & & & \\
\hline 4 & Anger & $\begin{array}{l}2.03 \\
(.86)\end{array}$ & .41 & $.11^{* * *}$ & $.16^{\star \star \star}$ & .003 & & & \\
\hline 5 & Tension & $\begin{array}{l}1.98 \\
(.97)\end{array}$ & .54 & $.04^{*}$ & .06 & -.02 & $.54^{\star * *}$ & & \\
\hline 6 & Joy & $\begin{array}{l}2.73 \\
(.80)\end{array}$ & .38 & $-.15^{\star \star *}$ & $-.18^{* * *}$ & .03 & $-.46^{\star \star \star}$ & $-.28^{\star \star \star}$ & \\
\hline 7 & Pride & $\begin{array}{l}2.70 \\
(.82)\end{array}$ & .40 & $-.22^{\star \star *}$ & $-.25^{\star \star *}$ & $.05^{\star *}$ & $-.49^{\star \star \star}$ & $-.26^{\star \star \star}$ & $.68^{\star * *}$ \\
\hline
\end{tabular}

Note. $N=114, k=3235$. Correlations are within-person.

${ }^{*} p<.05,{ }^{* *} p<.01,{ }^{* * *} p<.001$ 
EMOTIONS MEDIATE THE LINK BETWEEN GOAL FAILURE AND GOAL REVISION

Table S2

Results of the multilevel regression analyses predicting emotions by daily goal discrepancy (control group)

\begin{tabular}{lcccc}
\hline & Anger & Tension & Joy & Pride \\
\cline { 2 - 5 } & \multicolumn{4}{c}{ Estimates [CI] } \\
\cline { 2 - 5 } (Intercept) & $2.00^{* * *}$ & $1.97^{\star * *}$ & $2.79^{\star * *}$ & $2.77^{\star * *}$ \\
Goal & {$[1.84-2.16]$} & {$[1.79-2.14]$} & {$[2.64-2.94]$} & {$[2.61-2.93]$} \\
discrepancy & $.12^{* * *}$ & $.04^{*}$ & $-.14^{\star * *}$ & $-.19^{\star * *}$ \\
$R^{2}$ & {$[.09-.14]$} & {$[.02-.06]$} & {$[-.16--.11]$} & {$[-.22--.17]$} \\
& .014 & .002 & .019 & .038
\end{tabular}

Note. $N=114, k=3235$. Estimates are standardized.

${ }^{*} p<.05,{ }^{* *} p<.01,{ }^{* * *} p<.001$ 

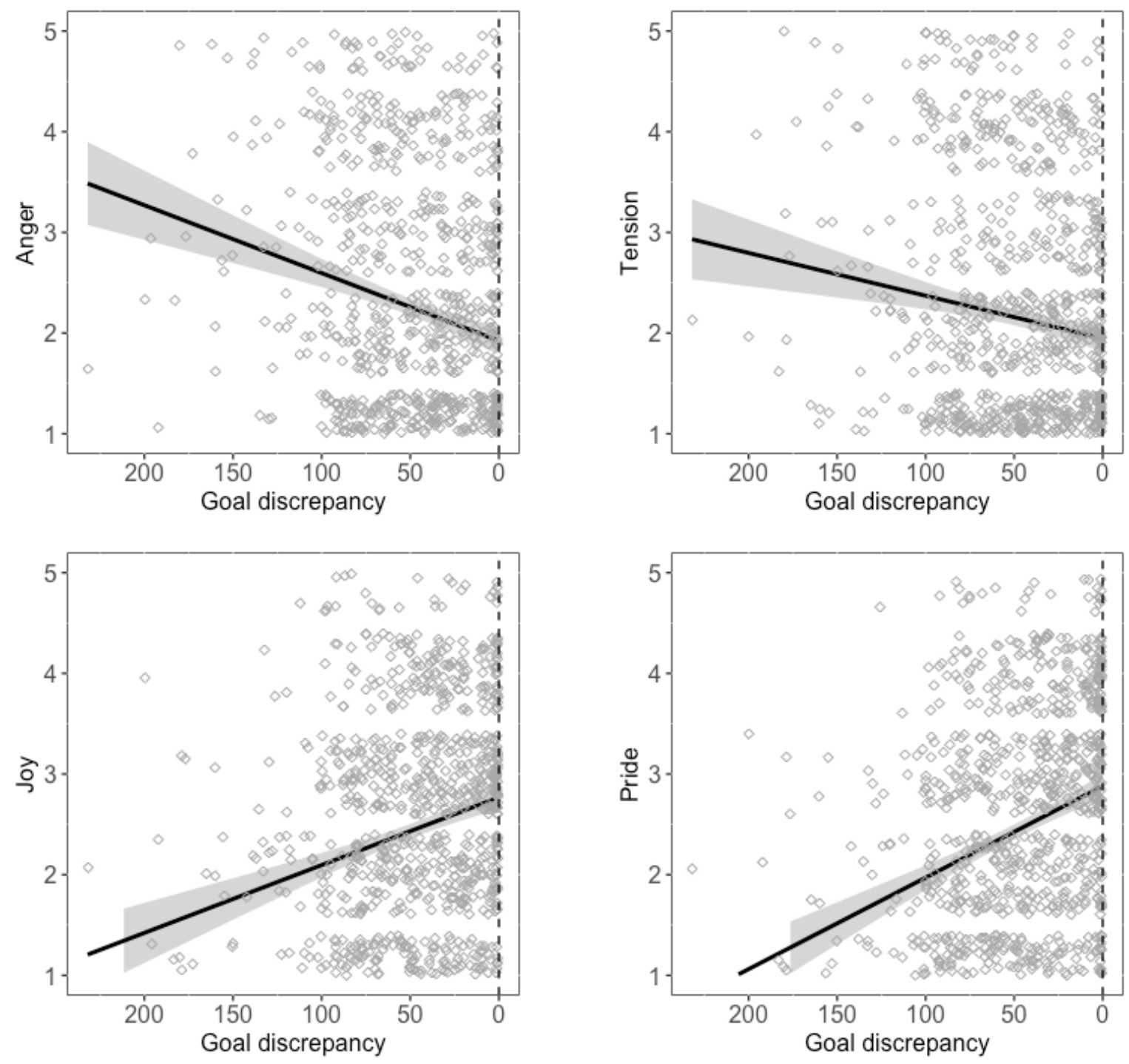

Figure S1. Achievement emotions after goal failure. Goal discrepancy (x-axis) depicts the discrepancy between the intended learning goal and the actual number of answered old exam questions on a given day. After goal failure, a larger discrepancy between the learning goal and the actual number of questions predicted more anger, more tension, less joy, and less pride. 


\section{EMOTIONS MEDIATE THE LINK BETWEEN GOAL FAILURE AND GOAL REVISION}

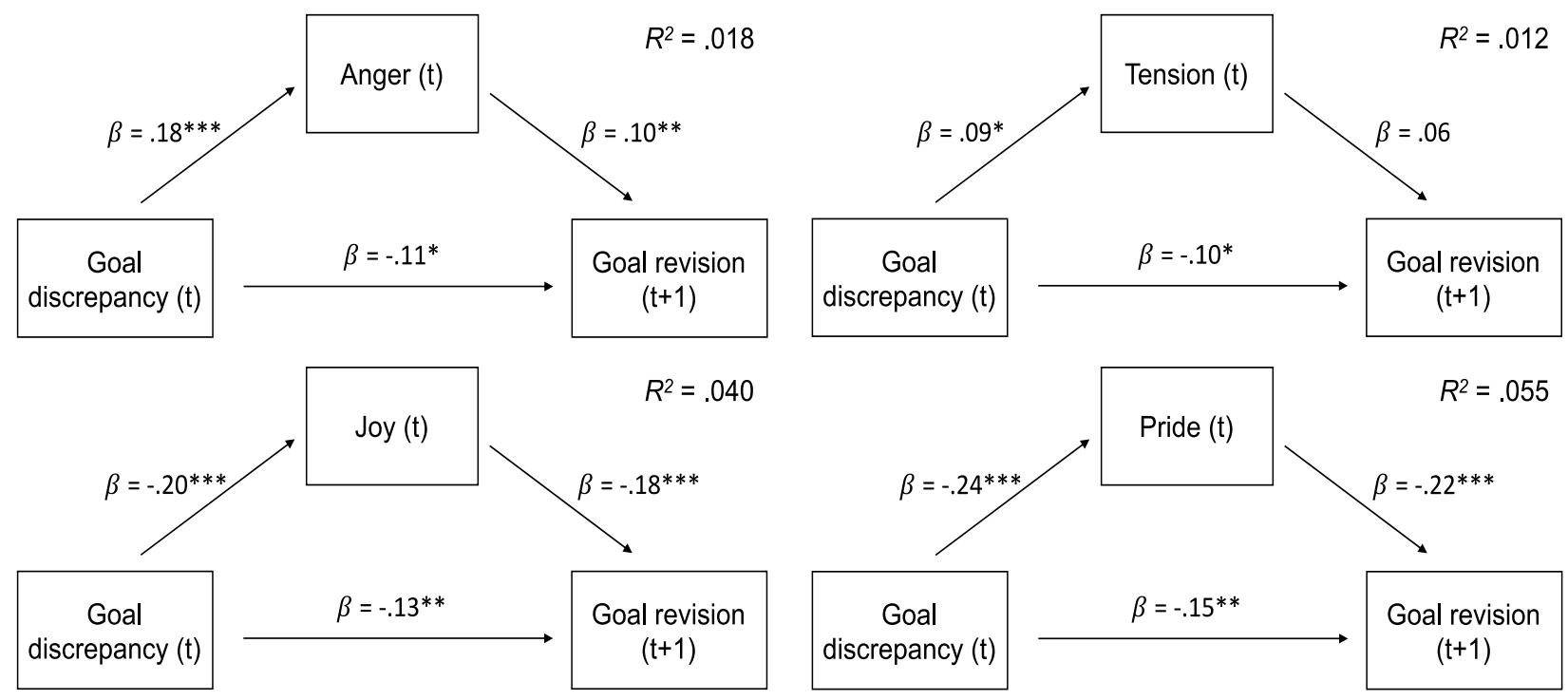

Figure S2. Within-person path analyses. After goal failure on day (t), goal discrepancy predicted subsequent goal revision on day $(t+1)$ indirectly via anger $(\beta=.019$, [.002.036 ], $p=.030)$, joy $(\beta=.038,[.018-.058], p=.010)$, and pride $(\beta=.055$, [.025 - .085], $p=.015)$, but not via tension $(\beta=.006,[-.003-.014], p=.216) . R^{2}$ refers to the explained within-person variance in goal revision.

${ }^{*} p<.05,{ }^{* *} p<.01,{ }^{* * *} p<.001$ 